Results Twenty-nine studies have been found from the referred theme. Several studies have been performed in animal models. Only three papers reported the effects of metals on sleepwake cycle. The first one was carried out with a population living in the surroundings of a metal recycling plant, where authors have detected that the exposed population had 2.3 chances to report sleep complaints. The other two studies observed children and pre-teens with high levels of lead in the blood have been associated to delay in the onset of sleep, longer duration of nocturnal awakenings, shorter duration of sleep, insomnia $(\mathrm{OR}=2.01)$ and longer daytime sleepiness $(\mathrm{OR}=2.90)$.

Discussion There are effects which link the environmental exposure to lead and cadmium with sleep complaints. Considering there are several production sectors, such as mining, and manufacturing processing industries that work with such metals and whose workers are in continuous shifts, it is likely that workers in these industries may suffered the effects of metal exposure and those leading to changes in biological rhythms caused by shift work. Financial Support: Faperj (E-10/225.935/2016).

\section{ACQUIRED DYSCHROMATOPSIA IN MEXICAN WORKERS OF A CHEMICAL INDUSTRY EXPOSED TO A MIXTURE OF ORGANIC SOLVENTS}

\begin{abstract}
${ }^{1}$ Mascorro-Villaseñor Arturo*, ${ }^{2} J u a ́ r e z-P e ́ r e z ~ C u a u h t e ́ m o c, ~{ }^{1}$ Martínez-Santiago Gladys, ${ }^{3}$ Omar Reséndez. ${ }^{1}$ Hospital Central Sur de Alta Especialidad Petróleos Mexicanos; ${ }^{2}$ Unidad de Investigación de Salud en el Trabajo. Centro Médico Nacional Siglo XXI; ${ }^{3}$ Refinería Ing. Antonio M. Amor
\end{abstract}

\subsection{6/oemed-2018-ICOHabstracts.830}

Introduction Acquired dyschromatopsia is an early and sensitive marker of ophthalmic neurotoxicity due to chronic exposure to various chemicals. The overall objective of this research was to identify changes in colour vision acquired the personnel occupationally exposed (POE) to a mixture of OS (benzene, toluene, xylen -BTX-).

Material and methods A cross-sectional study was conducted in two groups of workers; one occupational exposure to a mixture of OS and one without exposure to the chemical industry. The participants answered a questionnaire to explore risk factors acquired discromatopsia. Subsequently, the test Lanthony 15 desaturated (LD-15) in each eye was used to determine the ability of colour discrimination and Confusion Chromatic Index (CCI) was quantified. All ratio $>1$ was interpreted as abnormally increased. The data univariate and bivariate analysis were submitted. Association tests were implemented ( $t$ test, $\mathrm{Chi}^{2}$ and logistic regressions).

Results The total population was 142 workers, 5.4\% of whom had a profile consistent with congenital dyschromatopsia and were excluded from the final analysis. The group of 73 workers was exposed, while the unexposed group was 65 . The average age was 43.9 years $( \pm 10)$ and 42.7 years $( \pm 12)$, respectively. The prevalence of acquired dyschromatopsia in both eyes was higher for the exposed group; $8 \%$ in right eye and $9 \%$ in left eye, however, no statistically significant differences from the unexposed group. Quantification of CCI was slightly higher in the exposure group (1.09) compared to the group without exposure (1.08), although the differences between groups were not statistically significant $(p=0.73)$.

Discussion The results are consistent with those of other investigators; ICC ratio is higher in the exposed group, as well as the prevalence of acquired dyschromatopsia, being the most common for both groups.

\section{ELECTROENCEPHALOGRAPHIC STUDIES AMONG DRIVERS BEFORE AND AFTER TEST ON BUS SIMULATOR}

${ }^{1} \mathrm{P}$ Viebig*, ${ }^{2} \mathrm{~K}$ Polatynska, ${ }^{1} \mathrm{~W}$ Szymczak, ${ }^{1} \mathrm{~J}$ Litynska, ${ }^{1} \mathrm{~J}$ Siedlecka, ${ }^{1} \mathrm{E}$ Gadzicka, ${ }^{1}$ A Szyjkowska, ${ }^{1} \mathrm{M}$ Dania, ${ }^{1} \mathrm{M}$ Kosobudzki, ${ }^{1} \mathrm{H}$ Sinczuk-Walczak, ${ }^{1} \mathrm{~A}$ Bortkiewicz. ${ }^{1}$ Nofer Institute of Occupational Medicine, Lodz, Poland; ${ }^{2}$ Polish Mother's Memorial Hospital Research Institute, Lodz, Poland; ${ }^{3}$ University of Lodz, Department of Psychological Research Methodology and Statistics, Poland

\subsection{6/oemed-2018-ICOHabstracts.831}

Introduction The aim of the study was to evaluate the effect of the test on the simulator on the bioelectric activity of the brain of professionally active drivers.

Methods Electroencephalography registration was performed with the 32-channel recorder. Electrodes locations were specified by the International 10-20 system. The records were performed before the start of the test on the simulator, which enables full simulation of real road conditions (Exam I) and after its completion (Exam II). A recording was performed, with eyes closed, for $30 \mathrm{~min}$. At 2,5,6,23,25 min of the test, the eye was opened and closed, at the 8 th min. - a test of deep breathing (hyperventilation test $-3 \mathrm{~min}$ ) and intermittent photic stimulation. We used stimulation with frequencies of 3 , $6,9,12,15,18,21,24,27,30 \mathrm{~Hz}$ and back. 45 subjects were enrolled to study. All subjects were bus drivers aged 3158 years (43.5 \pm 7.9 years), seniority as a bus driver of 13.3 \pm 8.6 years. The frequency and amplitude of the basic activity of the brain was analysed and compared between left and right homologous EEG channels in Exam I and II.

Results The basic activity brain parameters were analysed at rest, 2-3 min hyperventilation and after activation attempts. In the Exam I hyperventilation revealed a statistically significant difference between basic rhythm frequencies $(p=0.043)$. In the left-side channels, the mean value was significantly higher than in the right-side channels $(10.49 \pm 1.34$ vs $10.30 \pm 1.19)$, the difference was not observed in the Exam II $(10.46 \pm 1.66$ vs $10.29 \pm 1.64, \mathrm{p}=0.397)$.

Discussion This difference could not be explained by the physiological response to hyperventilation. There were no differences between the baseline rhythm recorded at rest at both the first and second test. The explanation of these results requires further studies.

\section{Occupational Health and Development}

\section{CALLING OCCUPATIONAL HEALTH TO THE FOREFRONT}

Denise Minnie*. South African Society of Occupational Health Nurses, Johannesburg, South Africa

\subsection{6/oemed-2018-ICOHabstracts.832}

Introduction An overview was conducted of the exposure and impact Occupational Health has had in RSA when compared to Safety and the Environmental disciplines. Although Occupational Health eventually established a foothold in RSA during the industrial era of the early 1900's, the discipline appeared to have evolved much slower with limited recognition. A foundation to further develop evidence based strategies that could revitalise the 